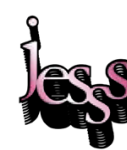

\title{
OPTIMIZATION OF COAGULATION-FLOCCULATION AND OZONATION PROCESSES FOR THE TREATMENT OF KRAFT PULP MILL EFFLUENT
}

\author{
Neranjala Kaushalya HERATH ${ }^{1}$, Yoshito OHTANI ${ }^{2}$ and Hideaki ICHIURA ${ }^{3}$ \\ ${ }^{1}$ Department of Forest Science, Graduate School of Agriculture, Kochi University \\ (B-200 Monobe, Nankoku, Kochi 783-8502 Japan) \\ E-mail:kaushalyai2002@yahoo.com \\ 2 Professor, Department of Forest Science, Kochi University \\ (B-200 Monobe, Nankoku, Kochi 783-8502 Japan) \\ E-mail: ohtani@kochi-u.ac.jp \\ 3 Associate Professor, Department of Forest Science, Kochi University, \\ (B-200 Monobe, Nankoku, Kochi 783-8502 Japan) \\ E-mail:ichiura@kochi-u.ac.jp
}

\begin{abstract}
A study on the effect of ozonation and coagulation- flocculation processes on kraft pulp mill effluents has been carried out. The objectives were to determine (1)best chemical combination for coagulationflocculation, (2)optimum $\mathrm{pH}$ for ozonation and to evaluate (3)suitability of ozonation as pre and post treatment of coagulation-flocculation. Removal efficiencies of color, turbidity and phenolic compounds were investigated under different conditions. Results indicated that initial acidic $\mathrm{pH}$ in the effluent is more favorable for ozonation at the experimented $\mathrm{O}_{3}$ flow rate. Use of $0.1 \mathrm{~g} / \mathrm{L} \mathrm{AlCl}_{3} .2 \mathrm{H}_{2} \mathrm{O}$ with $0.05 \mathrm{~g} / \mathrm{L}$ polyacrylamide gives the maximum reductions of color, turbidity and phenolic compounds in the effluent. Coagulation-flocculation followed by ozonation is a better system for the treatment of kraft pulp mill effluent. This system can reduce all the three parameters by about $90 \%$.
\end{abstract}

Key Words: ozonation, coagulation-flocculation, kraft pulp mill effluent, color, phenolic compounds, turbidity

\section{INTRODUCTION}

The pulp and paper industry is a major industrial sector utilizing a significant amount of water during processing. It also contributes to the environmental pollution significantly. The effluents from the industry cause slime growth, thermal impacts, scum formation, color problems and loss of aesthetic beauty in the environment. They also increase the amount of toxic substances in the water causing death to the zooplankton and fish, profoundly affecting the terrestrial ecosystem ${ }^{1)}$.

Different processes are employed for the making of paper and there is a significant difference in quality of wastewaters from the pulp and paper making operations. This is due to the diversity of processes and chemicals used ${ }^{2}$. The black alkaline liquor released by paper mills contributes only $10-15 \%$ of the total wastewater, but contributes approximately to $95 \%$ of the total pollution load of pulp and paper mill effluents ${ }^{3)}$.

Lignin and its derivatives are difficult to degrade naturally because of the strong linkages within their molecular structures ${ }^{4)}$. Due to this fact, even though the conventional biological treatment processes are effective in decreasing the organic matter in the effluents, they have little effect on decolorization of the effluents.

Advance Oxidation Processes (AOPs) are being researched and used for the treatment of these refractory compounds. In AOPs' hydroxyl radicals $\left(\mathrm{OH}^{\circ}\right)$ are generated and used as the oxidizing agent. $\mathrm{OH}^{\bullet}$ is a powerful oxidizing agent with an oxidation potential of $2.33 \mathrm{~V}$ and exhibits a faster rate of oxidation reaction compared to that of conventional oxidants, such as hydrogen peroxide or potassium 
permanganate ${ }^{4)}$.

Ozonation is one of the existing AOPs which is being widely used for disinfection. Theoretically ozone is able to oxidize both inorganics and organics to their highest oxidation states, depending on the molecular selectivity and decay rates. The decomposition rate of ozone is affected by the presence of inorganic/ organic species in the reaction medium. Ozone reacts with organic compounds dissolved in water through either direct ozone attack or indirect free radical attack. The radical oxidation is less selective and predominates under basic conditions, while direct oxidation is more selective and predominates under acidic conditions ${ }^{5)}$.

A major limitation of the ozonation process is the relative high cost of ozone generation coupled with the very short half life period of ozone. Therefore it is always necessary to generate ozone at site.

Chemical coagulation-flocculation followed by settling is a probed technique for the treatment of high suspended solids wastewater especially those formed with colloid matter. Coagulation is mainly induced by inorganic metal salts, e.g. aluminium and ferric sulphates and chlorides. Polyelectrolytes of various structures, e.g. polyacrylamides (PAA), chitosan, polysaccharides, polyvinyl and many others are usually used as flocculants to enhance the formation of larger flocs in order to improve the rate of settling ${ }^{6}$.

Several researchers have carried out studies on ozonation $^{4778)}$ and coagulation- flocculation ${ }^{699}$ using effluents originated by different types of pulp and paper manufacturing processes. But information on the combined treatment of the above two methods are limited. Ramos ${ }^{10)}$ has evaluated the effect of chemical precipitation and ozonation conditions on the decolorization kinetics in the residual water of a paper industry.

Kraft pulp effluent is the residual coming from the kraft pulping process in which wood chips are treated at high temperature with cooking chemicals, $\mathrm{NaOH}$ and $\mathrm{Na}_{2} \mathrm{~S}$. Therefore the effluent contains residuals of cooking chemicals, lignin compounds as well as extractives and hydroxyl acids coming from the raw materials ${ }^{11)}$. A normal procedure exercised in most modern pulp mills is concentration in multiple effect evaporators, followed by incineration, smelting and causticization to recover $85 \%$ of the cooking chemicals $^{12)}$. Most of the organic substances in kraft pulp effluent are burnt off, however dilute effluent mostly coming from pulp washing always result in refractory wastewater.

The present work focuses on the application of ozonation in the treatment of kraft pulp mill effluent in combination with coagulation-flocculation; especially for the reduction of color, turbidity and phenolic compounds. The objectives were to determine (1) best chemical combination for coagulation-flocculation, (2) optimum $\mathrm{pH}$ for ozonation and to evaluate (3) suitability of ozonation as pre and post treatment of coagulation-flocculation.

\section{MATERIALS AND METHODS}

\section{(1) Materials}

The wastewater samples for the experiments were sourced from a kraft pulp mill in Ehime Prefecture, Japan. $\mathrm{Al}_{2} \mathrm{SO}_{4} \cdot 14 \mathrm{H}_{2} \mathrm{O}, \mathrm{AlCl}_{3} \cdot 2 \mathrm{H}_{2} \mathrm{O}$ and $\mathrm{CaCl}_{2} \cdot 2 \mathrm{H}_{2} \mathrm{O}$ were used as coagulants while PAA and sodium alginate were used as flocculants. All the chemicals used were of analytical reagent grade and used without further purification.

Ozonizer OZM 5006 (Nomura Electronics Co. Ltd. Japan) with a flow rate of $0.2 \mathrm{~g} / \mathrm{m}^{3}(76 \mathrm{mg} / \mathrm{hr})$ was used as the ozone generator.

\section{(2) Methods}

Wastewater samples were initially analyzed for the determination of COD(chemical oxygen demand), SS(suspended solids) and TDS(total dissolving substances) according to the standard methods of examination of water and wastewater ${ }^{13)}$. The average values of three samples are tabulated in Table 1.

Table 1 The average characteristics of the kraft pulp mill effluent

\begin{tabular}{|lr|}
\hline Parameter & Value \\
\hline $\mathrm{pH}$ & 11.5 \\
$\mathrm{COD}(\mathrm{g} / \mathrm{L})$ & 160.1 \\
$\mathrm{SS}(\mathrm{g} / \mathrm{L})$ & 5.5 \\
$\mathrm{TDS}(\mathrm{g} / \mathrm{L})$ & 170.7 \\
Dissolved inorganic solids $(\mathrm{g} / \mathrm{L})$ & 73.8 \\
Dissolved $\mathrm{Ca}^{2+}(\mathrm{g} / \mathrm{L})$ & 1.2 \\
Dissolved $\mathrm{Na}^{+}(\mathrm{g} / \mathrm{L})$ & 338.7 \\
\hline
\end{tabular}

Prior to ozonation or coagulation-flocculation, kraft pulp mill effluents were filtered using Advantec No.2 filter papers. Effluents for the experiments were prepared by diluting the filtered effluent by 1000 times using distilled water. This diluted solution is equivalent to the residual effluent released by the manufacturing process. This effluent is not having enough organic or chemical compounds for chemical or energy recovery. Every experiment was done in triplicate.

UV/Vis absorption spectra in a UV/Vis spectrophotometer (Hitachi U-2810) were obtained at wavelengths of $465 \mathrm{~nm}, 450 \mathrm{~nm}$ and $280 \mathrm{~nm}$ to monitor the removal efficiency. These wavelengths correspond to different properties of wastewater; 
i.e. $465 \mathrm{~nm}$ corresponds to visible color $^{14)}, 450 \mathrm{~nm}$ corresponds to turbidity, $280 \mathrm{~nm}$ is related to aromatic groups like phenols, which are usually present in these kinds of effluents ${ }^{15)}$.

\section{a) Coagulation-flocculation of the effluent}

Coagulation-flocculation experiments were conducted using different chemical combinations, at different dosages and initial effluent $\mathrm{pH}$ levels. Details of those combinations are tabulated in Table 2. The experiments were performed in jars, using sample volumes of $200 \mathrm{~mL}$. Sample $\mathrm{pH}$ values were adjusted using small volumes of concentrated $\mathrm{H}_{2} \mathrm{SO}_{4}$. After $\mathrm{pH}$ adjustment, coagulant was added at varying dosages. It was then followed by the addition of flocculant at varying dosages. All the samples were immediately stirred rapidly for 30 seconds. They were then stirred slowly for $5 \mathrm{~min}$ and allowed to settle down for $2 \mathrm{hrs}$. UV/Vis spectrophotometer absorption values were taken initially before addition of chemicals and at every 30 min period during settling down.

Table 2 Different conditions for coagulation-flocculation experiments

\begin{tabular}{|c|c|c|c|c|}
\hline Coagulant & $\begin{array}{l}\text { Coag. } \\
\text { dose } \\
(\mathrm{g} / \mathrm{L})\end{array}$ & Flocculant & $\begin{array}{l}\text { Floc. } \\
\text { dose }\end{array}$ & $\mathrm{pH}$ \\
\hline \multirow[t]{2}{*}{$\begin{array}{r}\mathrm{Al}_{2} \mathrm{SO}_{4} \cdot 14 \mathrm{H}_{2} \\
\mathrm{O}\end{array}$} & \multirow{2}{*}{$\begin{array}{l}0 \\
0.06 \\
0.08 \\
0.1\end{array}$} & PAA & $\begin{array}{l}0.01 \mathrm{~g} / \mathrm{L} \\
0.05 \mathrm{~g} / \mathrm{L}\end{array}$ & \multirow{2}{*}{$\begin{array}{c}10 \\
5 \\
3\end{array}$} \\
\hline & & $\begin{array}{l}\text { Sodium } \\
\text { alginate }\end{array}$ & $0.01 \%$ & \\
\hline \multirow[t]{2}{*}{$\mathrm{AlCl}_{3} \cdot 2 \mathrm{H}_{2} \mathrm{O}$} & \multirow{2}{*}{$\begin{array}{l}0 \\
0.1 \\
0.5 \\
1\end{array}$} & PAA & $0.05 \mathrm{~g} / \mathrm{L}$ & \multirow{2}{*}{$\begin{array}{c}10 \\
5 \\
3\end{array}$} \\
\hline & & $\begin{array}{l}\text { Sodium } \\
\text { alginate }\end{array}$ & $0.01 \%$ & \\
\hline $\mathrm{CaCl}_{2} \cdot 2 \mathrm{H}_{2} \mathrm{O}$ & $\begin{array}{l}0 \\
0.1 \\
0.2 \\
0.3\end{array}$ & $\begin{array}{l}\text { Sodium } \\
\text { alginate }\end{array}$ & $\begin{array}{l}0.05 \% \\
0.01 \%\end{array}$ & $\begin{array}{c}10 \\
5 \\
3\end{array}$ \\
\hline
\end{tabular}

\section{b) Ozonation of the effluent}

Ozonation was performed ina reactor with a capacity of $250 \mathrm{~mL}$. The ozone stream was continuously introduced to the sample as bubbles through a glass filter at the bottom of the reactor. Ozone flow rate was $0.2 \mathrm{~g} / \mathrm{m}^{3}(76 \mathrm{mg} / \mathrm{hr})$. Effluent samples were ozonated for $3 \mathrm{hrs}$ and UV/Vis spectrophotometer absorption values were taken initially as well as at every $30 \mathrm{~min}$ period during ozonation.

c) Ozonation as pre and post treatment to coagulation-flocculation

Experiments were conducted aiming at evaluating the suitability of ozonation as a treatment method before or after coagulation-flocculation. As for first approach, coagulation-flocculation was done according to the method described in section a) for $500 \mathrm{~mL}$ of diluted effluent. The chemicals used were $0.1 \mathrm{~g} / \mathrm{L} \mathrm{AlCl}{ }_{3} \cdot 2 \mathrm{H}_{2} \mathrm{O}$ and $0.05 \mathrm{~g} / \mathrm{L}$ PAA at $\mathrm{pH}$. After allowing $2 \mathrm{hrs}$ for settling, the supernatant was separated and ozonated for $3 \mathrm{hrs}$.

As for the other approach, the diluted effluent at pH5 was ozonated for $3 \mathrm{hrs}$. Ozonated effluent was then treated with $0.1 \mathrm{~g} / \mathrm{L} \mathrm{AlCl} 3.2 \mathrm{H}_{2} \mathrm{O}$ and $0.05 \mathrm{~g} / \mathrm{L}$ PAA according to the method described in section a) and allowed to settle for $2 \mathrm{hrs}$.

\section{RESULTS AND DISCUSSION}

\section{(1) Coagulation-flocculation of the effluent}

Maximum removal efficiencies obtained by coagulation-flocculation experiments are summarized in Table 3.

Table 3 Maximum removal efficiencies by coagulationflocculation.

\begin{tabular}{|lcc|}
\hline $\begin{array}{l}\text { Coagulant }+ \\
\text { Flocculant }\end{array}$ & $\begin{array}{c}\mathrm{Al}_{2} \mathrm{SO}_{4} \cdot 14 \mathrm{H}_{2} \mathrm{O}+ \\
0.05 \mathrm{~g} / \mathrm{L} \text { PAA }\end{array}$ & $\begin{array}{l}\mathrm{AlCl}_{3} \cdot 2 \mathrm{H}_{2} \mathrm{O}+ \\
0.05 \mathrm{~g} / \mathrm{L} \text { PAA }\end{array}$ \\
\hline Coagulant $\operatorname{dose}(\mathrm{g} / \mathrm{L})$ & 0.1 & 0.1 \\
$\mathrm{pH}$ & 4 & 5 \\
$\%$ removal of color & 83 & 89 \\
$\%$ removal of turbidity & 85 & 89 \\
$\%$ removal of phenolic & & 83 \\
compounds & 78 & \\
\hline
\end{tabular}

In the coagulation process, the aggregation of colloidalparticlesoccurs through chargeneutralization and sweep-floc effects. The $\mathrm{pH}$ range of $4-5.5$ is appropriate for charge neutralization between the positively charged coagulant and negatively charged colloids. On the other hand, as for metal coagulants, such as $\mathrm{Al}$ or $\mathrm{Fe}$ salts, their ability of removing turbidity is achieved mainly by the adsorption of amorphous solid state aluminium hydroxide, $\mathrm{Al}(\mathrm{OH})_{3(\mathrm{~S})}$. For the formation of $\mathrm{Al}(\mathrm{OH})_{3(\mathrm{~S})}$, the $\mathrm{pH}$ range of 6-8 is favorable because the $\mathrm{Al}$ ions require sufficient alkalinity to form it. Thus in the combined action of charge neutralization and sweep-floc point of view, $\mathrm{pH} 5-8$ is the optimal range for turbidity reduction ${ }^{9}$.

As per the results obtained, the optimum $\mathrm{pH}$ for coagulation-flocculation exists in the range of 4-5. This establishes the fact that in coagulationflocculation of kraft paper mill effluent, charge neutralization, which is dominant in the acidic $\mathrm{pH}$, plays an important role in forming the settleable floc. The chemical combination of $0.1 \mathrm{~g} / \mathrm{L} \mathrm{AlCl}_{3} .2 \mathrm{H}_{2} \mathrm{O}$ and $0.05 \mathrm{~g} / \mathrm{L}$ PAA at $\mathrm{pH} 5$ gives the maximum reduction in color, turbidity and phenolic compounds in the diluted effluent, with efficiencies $89 \%, 89 \%$ and $83 \%$, respectively. 


\section{(2) Ozonation of the effluent}

Fig.1 and Fig.2 show the percentage reductions of phenolic compounds and color during the $3 \mathrm{hrs}$ of ozonation. Change of $\mathrm{pH}$ during ozonation is shown in Fig.3.

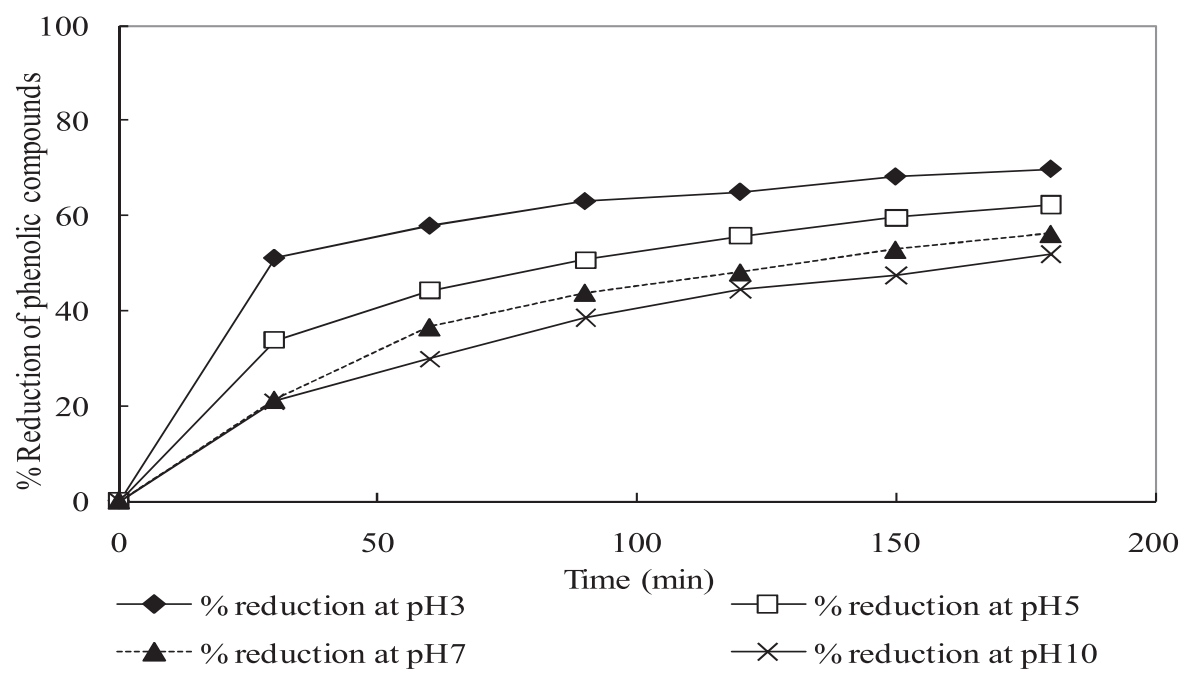

Fig.1 Effect of $\mathrm{pH}$ on the percentage reduction of phenolic compounds during ozonation

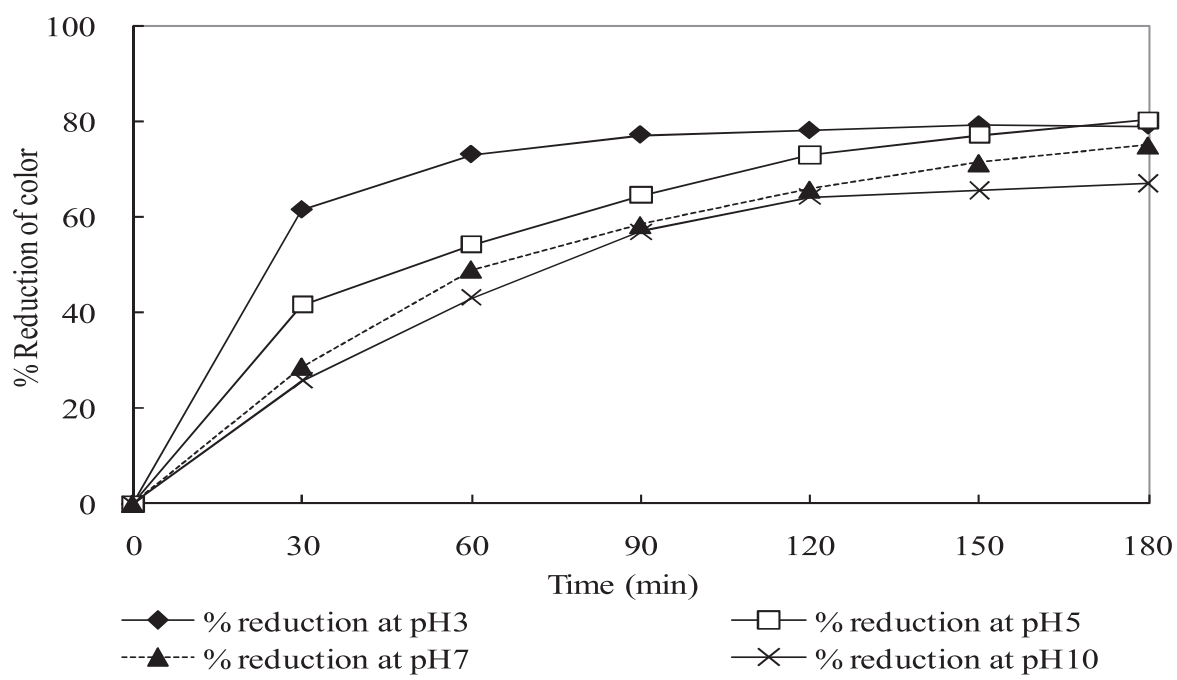

Fig.2 Effect of $\mathrm{pH}$ on the percentage reduction of color during ozonation.

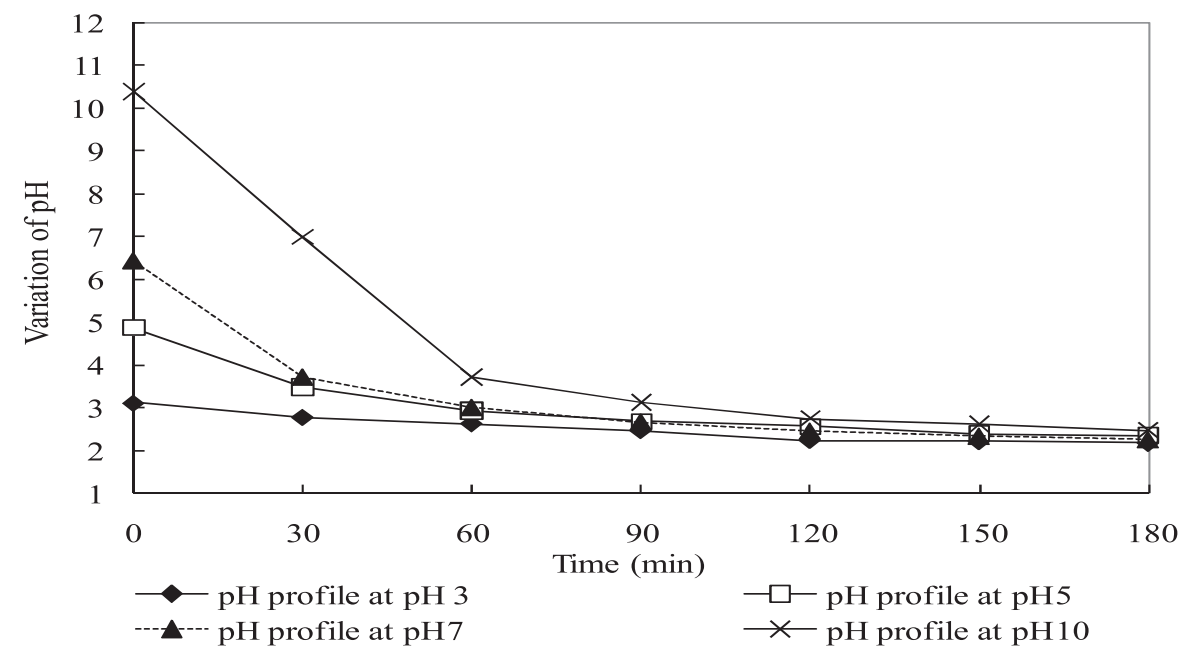

Fig.3 Change of $\mathrm{pH}$ during ozonation. 
Reduction percentage of phenolic compounds increases with lowering $\mathrm{pH}$. The maximum removal after $3 \mathrm{hrs}$ of ozonation is $70 \%$ and the minimum is $52 \%$ at $\mathrm{pH}$ of 3 and 10 , respectively. This result shows that ozonation performs better in terms of degradation of phenolic compounds under acidic conditions, which is in agreement with the published results ${ }^{16)}$.

Variation of color and turbidity has a similar trend. At the end of $3 \mathrm{hrs}$ ozonation reduction of color at $\mathrm{pH} 3,5,7$, and 10 are $79 \%, 80 \%, 75 \%$ and $67 \%$, respectively. This also confirms the fact that ozonation has higher efficiency at low initial $\mathrm{pH}$ of the effluent.

Experimental results show that the rates of decomposition of phenolic compounds as well as reduction of color are high within an initial hour. Thereafter the rate lowers, showing a tendency to become almost constant at some point of time. This observation can be explained in the following way.

The decolorization and decomposition of phenolic compounds occur in two distinct regions: (1) the first region is, an initial hour where reduction efficiency is high and (2) the other region is, after an hour, gradual reduction of reduction efficiency ${ }^{4}$. The higher initial reduction rate is due to the higher reactivity of ozone with the relatively fragile compounds in effluent. Less availability of easily oxidizable structures makes further ozonation sluggish.

The $\mathrm{pH}$ values of samples decrease with ozonation and converge to a value of around 2 after $3 \mathrm{hrs}$ of ozonation(Fig.3).Degradationofphenolic compounds into acyclic, acidic compounds such as muconic acid $^{17)}{ }^{18)}$ can be the reason for this characteristic in $\mathrm{pH}$ reduction. Muconic acid is supposed to be easily formed within first hour, then further decomposed into other acidic compounds, such as oxalic acid etc. and finally converted to carbon dioxide. But the latter reactions seem to be much slower than the former reaction. It may be a reason why the samples having higher initial $\mathrm{pH}$ indicate a rapid decrease of $\mathrm{pH}$ during ozonation although decomposition of phenolic compounds is larger at lower initial pH (Fig.1).

\section{(3) Ozonation kinetics}

Kinetic investigations on the decomposition reactions of phenolic compounds by ozonation have found to be of the first order with almost constant reaction coefficients ${ }^{19)}$ 20) 21 . These experimental analyses have been conducted using aqueous solutions of different types of phenols. Since the pure compounds follow first order reaction kinetics, the compounds available in kraft mill effluent can also be assumed to follow the same order.

Decomposition kinetics of phenolic and color compounds were investigated, assuming the reactions have the first order kinetics. Fig. 4 and Fig.5 show the graphs of $\ln \left[\mathrm{A}_{0} / \mathrm{A}\right]$ vs time t. In Fig.4 $\mathrm{A}_{0}$ and $\mathrm{A}$ correspond to initial phenolic compound concentration and phenolic compound concentration at any time t, respectively. Fig.5 represents the same parameters related to color.

Fig.4 shows near linear characteristics and it proves that the decomposition of phenolic compounds existing in the kraft pulp mill effluent have approximately the first order reaction kinetics in this experiment.

However according to Fig.5 the decomposition of color compounds hardly fit to the first order variation. The existence of compounds other than the phenolics which contributes to the color of the solution can be the reason of this deviation. Even though the phenolic compounds follow the first order reaction kinetics the others might not behave in the similar manner.

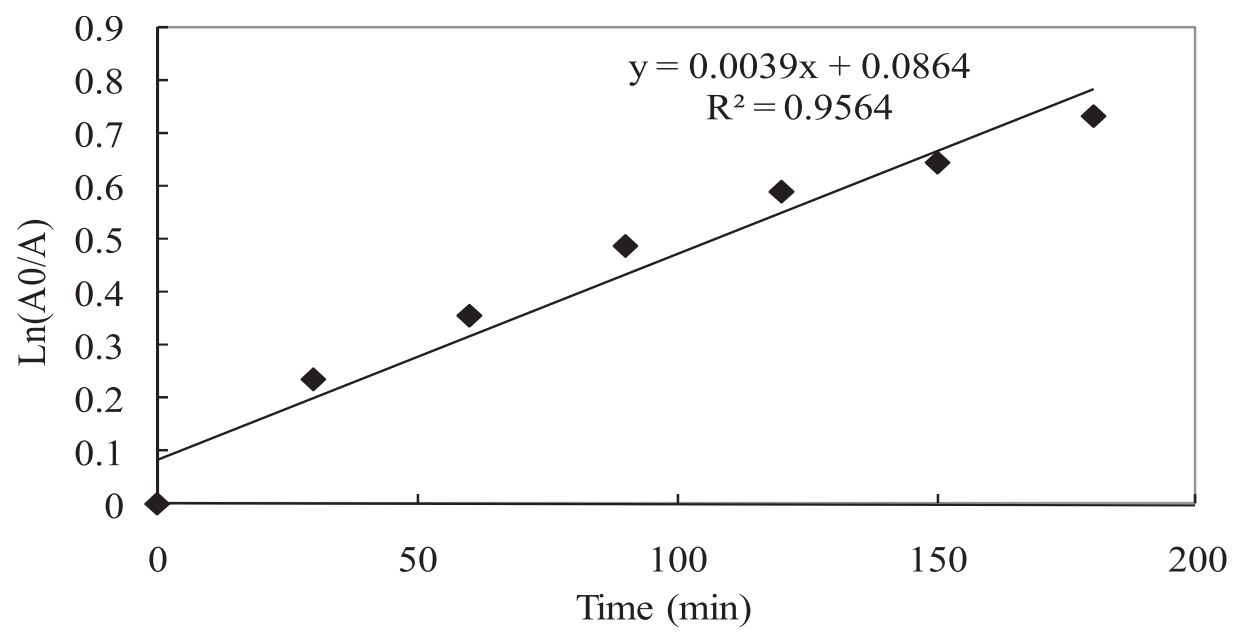

Fig.4 Change of the concentration of phenolic compounds at $\mathrm{pH} 10$. 


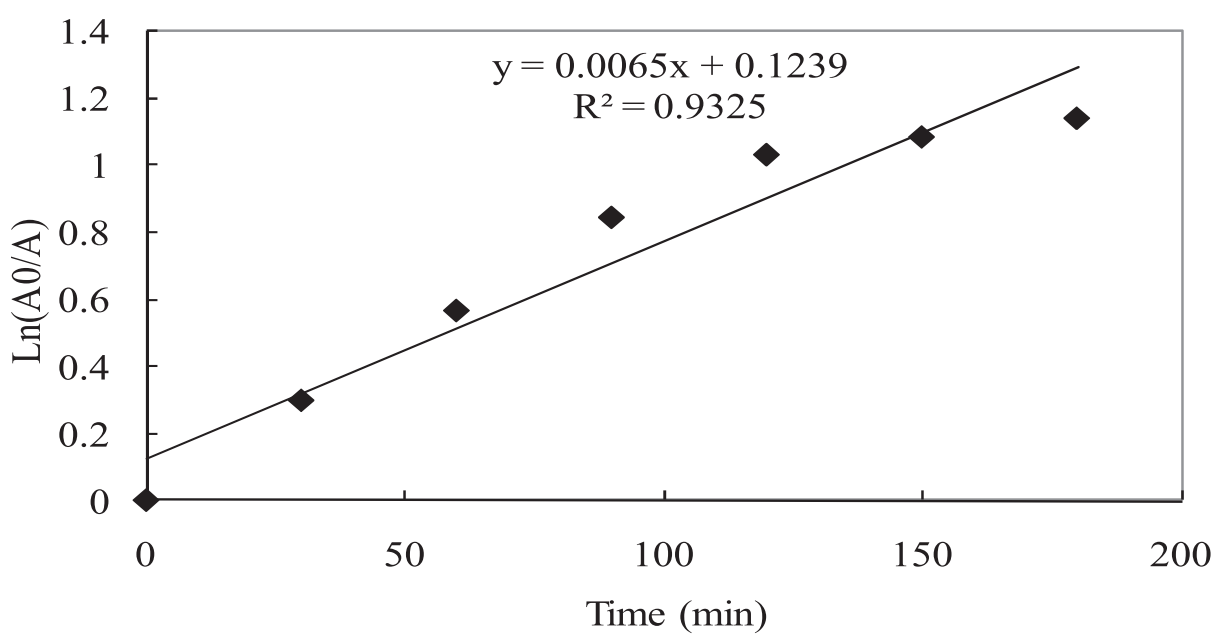

Fig.5 Change of the concentration of color compounds at $\mathrm{pH} 10$.

(4) Ozonation as pre and post treatment to coagulation-flocculation

Percentage reduction of phenolic compounds and color is shown in Fig.6 and Fig.7, respectively. Fig.6 corresponds to coagulation- flocculation followed by ozonation, while Fig.7 corresponds to ozonation followed by coagulation- flocculation.

As seen in Fig.6, the reduction of phenolic compounds by coagulation-flocculation followed by ozonation is $93 \%$ - out of which coagulationflocculation accounts for $83 \%$, while $10 \%$ is due to ozonation.

When ozonation is followed by coagulationflocculation, as shown in Fig. 7, the reduction of phenolic compounds is $59 \%$. Out of it, the initial ozonation accounts for $57 \%$, while coagulationflocculation accounts for only $2 \%$.

The meaning of results obtained above can be interpreted as follows: During coagulation- flocculation and settling, high molecular weight organic compounds end up in the sediment. The low molecular weight compounds that remain in the supernatant are further oxidized during ozonation ${ }^{22)}$ leading to higher reduction of phenolic compounds. On the other hand, initial ozonation degrades phenolic compounds into low molecular weight compounds, which are less removable by coagulationflocculation.

According to Fig.6 and Fig.7, it is apparent that what brings in the reduction of effluent color is whatever the initial treatment step, regardless of whether it is coagulation-flocculation or ozonation.

There is virtually no effect on color reduction from the second treatment method that follows. In addition, when coagulation-flocculation is the second method, there is a decrease in the clarity after adding chemicals, due to the formation of flocs.

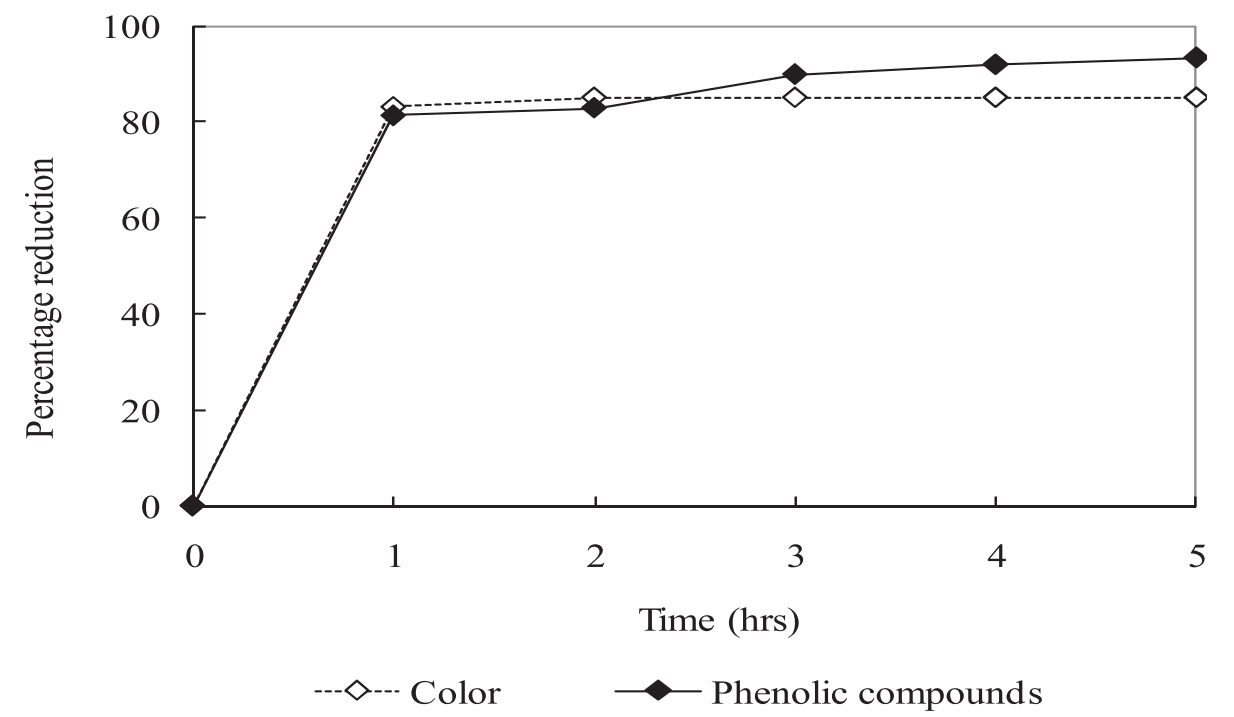

Fig.6 Percentage reduction of color and phenolic compounds with initial coagulation-flocculation ( $0-2$ hrs $)$ followed by ozonation (2-5 hrs). 


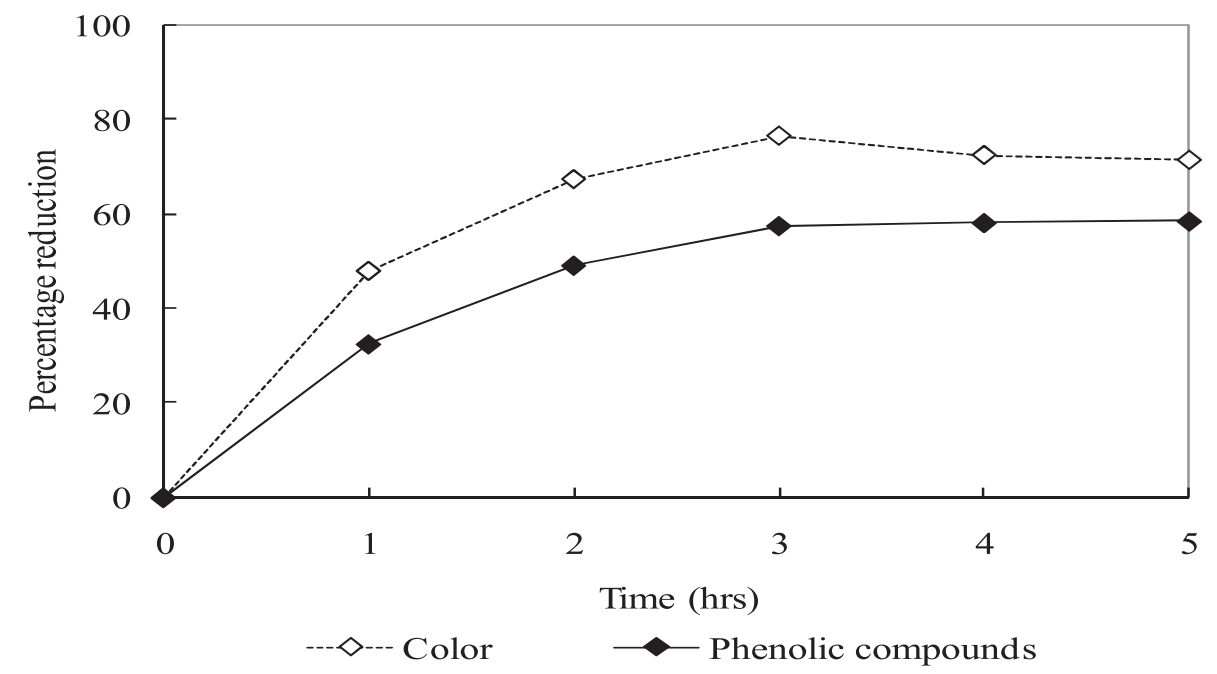

Fig.7 Percentage reduction of color and phenolic compounds with initial ozonation (0-3 hrs) followed by coagulation-flocculation (3-5 hrs).

\section{CONCLUSIONS}

The results of the study can be summarized as below.

More than $80 \%$ of reductions in color, turbidity and phenolic compounds can be achieved by using $0.1 \mathrm{~g} / \mathrm{L} \mathrm{AlCl}_{3} .2 \mathrm{H}_{2} \mathrm{O}$ with $0.05 \mathrm{~g} / \mathrm{L}$ PAA at $\mathrm{pH} 5$.

After coagulation-flocculation, $1 \mathrm{hr}$ settling period is sufficient enough to settle almost all the flocs formed.

Ozonation is more effective in the treatment of kraft pulp mill effluent under acidic conditions.

Decomposition of phenolic compounds in the effluent by ozonation has a first order reaction kinetics.

In the case of treating kraft paper mill effluent, ozonation is more suitable after the chemical coagulation-flocculation. This sequence of combined treatment is capable of producing colorless and phenolic compounds-free effluent.

ACKNOWLEDGMENT: Financial support for this research provided by the Japanese Government Monbukagakusho Scholarship is greatly appreciated.

\section{REFERENCES}

1) Pokhrel D. and Viraraghavan T.: Treatment of pulp and paper mill wastewater- a review, Science of the Total Environment, Vol. 333, pp. 37- 58, 2004.

2) Thompson G., Swain J., Kay M. and Forster C.F.: The treatment of pulp and paper mill effluent: a review, Bioresource Technology, Vol. 77, pp. 275- 286, 2001.

3) Buzzini A. P. and Pires E.C.: Cellulose pulp mill effluent treatment in an upflow anaerobic sludge blanket reactor, Process Biochemistry, Vol. 38, pp. 707- 713, 2002.

4) Kreetachat T., Damrongsri M., Punsuwon V., Vaithanomst P., Chiemchaisri C. and Chomsurin C.: Effects of ozonation process on lignin- derived compounds in pulp and paper mill effluents, Journal of Hazardous Material, Vol. 142, pp. 250-
$257,2007$.

5) Oguz E. and Keskinler B.: Removal of color and COD from synthetic textile wastewaters using $\mathrm{O}_{3}, \mathrm{PAC}, \mathrm{H}_{2} \mathrm{O}_{2}$ and $\mathrm{HCO}_{3}{ }^{-}$ , Journal of hazardous Materials, Vol. 151, No. 2-3, pp. 753$760,2008$.

6) AhmadA.L., Wong S.S., Teng T.T. andZuhairiA.: Improvement of alum and $\mathrm{PACl}$ coagulation by polyacrylamides for the treatment of pulp and paper mill wastewater, Chemical Engineering Journal, Vol. 137, pp. 510- 517, 2008.

7) Freire R. S., Kunz A. and Durán N.: Some chemical and toxicological aspects about paper mill effluent treatment with ozone, Journal of Environmental Technology, Vol. 21, pp. 717- 721, 2000.

8) Yamamoto S., Koga C., Hosomura H. and Okayama T.: Ozone treatments of bleached kraft pulp and waste paper, Japan Tappi Journal, Vol. 55, No.4, pp. 90- 97, 2001.

9) Wang J. P., Chen Y. Z., Ge X. W. and Yu H. Q.: Optimization of coagulation- flocculation process for a paper- recycling wastewater treatment using response surface methodology, Colloids and Surfaces A: Physicochemical and Engineering Aspects, Vol. 302, pp. 204- 210, 2007.

10) Ramos D. S., Poznyak T., Chairez I. and Córdova R.: Remediation of lignin and its derivatives from pulp and paper industry wastewater by the combination of chemical precipitation and ozonation, Journal of Hazardous Material, Vol. 169, pp. 428- 234, 2009.

11) Wallberg O. and Jönsson A. S.: Influence of the membrane cut off during ultrafiltration of kraft black liquor with ceramic membranes, Chemical Engineering Research and Design, Vol. 81, No. 10, pp 1379- 1384, 2003.

12) Bhattacharjee S., Datta S. and Bhattacharjee C.: Performance study during ultrafiltration of kraft black liquor using rotating disk membrane module, Journal of Cleaner Production, Vol. 14, pp 497- 504, 2006.

13) American Public Health Association: Standard methods for the examination of water and wastewater, $21^{\text {st }}$ Edition, USA, 2005.

14) Biermann C. J.: Essentials of pulping and papermaking, Academic Press, Inc., USA, pp. 283- 297, 1993.

15) Rodrigues A. C., Boroski M., Shimada N. S., Garcia J. C., Nozaki J. and Hoika N.: The treatment of paper pulp and paper mill wastewater by coagulation- flocculation followed by heterogeneous photocatalysis, Journal of Photochemistry and Photobiology A: Chemistry, Vol. 194, No. 2, pp. 1- 10, 2008. 
16) Boncz M. A., Bruning H., Bulkens W. H., Sudhotler E. J. R., Harmsen G. H. and Bijsterbosch J. W.: Kinetic and mechanistic aspects of the oxidation of chlorophenols by ozone, Water Science Technology, Vol. 35, pp. 65-72, 1997.

17) Khudoshin A. G., Mitrofanova A. N. and Lunin V. V.: Kinetics and mechanism of the reactions of ozone with guaiacol, veratrol, and veratrol derivatives, Russian Chemical Bulletin, International Edition, Vol. 57, No. 2, pp 283- 288, 2008.

18) Lin S. Y. and Dence C. W.: Methods in Lignin Chemistry, Springer Verlag Berlin Heidelberg, pp. 3- 17, 1992.

19) Turhan K. and Uzman S.: Removal of phenol from water using ozone, Desalination, Vol. 229, pp. 257- 263, 2008.

20) Anotai J., Wuttipong R. and Visvanathan C.,: Oxidation and detoxification of pentachlorophenol in aqueous phase by ozonation, Journal of Environmental Management, Vol. 85, pp. 345- 349, 2007.

21) Wu J., Rudy K. and Spark J.: Oxidation of aqueous phenol by ozone and peroxidase, Advances in Environmental Research, Vol. 4, pp. 339- 346, 2000.

22) Stephenson R. J. and Duff S. J. B.: Coagulation and precipitation of a mechanical pulping effluent- I. Removal of carbon, color and turbidity, Water Resource, Vol. 30, No.4, pp. 781-792, 1996.

(Received September 25, 2009) 